SOUZA, N.A.; JASMIM, J. Crescimento de singônio com diferentes tutores e substratos à base de mesocarpo de coco. Horticultura Brasileira, Brasília, v.22, n.1, p.39-44, jan-mar 2004.

\title{
Crescimento de singônio com diferentes tutores e substratos à base de mesocarpo de coco
}

\author{
Nádia A. de Souza; Janie Jasmim \\ UENF, Av. Alberto Lamego 2000, 28013-602 Campos dos Goytacazes-RJ; E-mail: souzan@uenf.br; janie@uenf.br
}

\begin{abstract}
RESUMO
Diferentes tutores e substratos foram utilizados para avaliar o cultivo de singônio (Syngonium angustatum Schott) em experimento instalado sob delineamento inteiramente casualizado, em esquema fatorial $(2 \times 2)$, com seis repetições, três vasos por parcela e duas plantas por vaso. Os tratamentos avaliados foram (1) substrato comercial (SC), com tutor de xaxim (X); (2) substrato comercial, com tutor de mesocarpo de coco triturado (MCT); (3) substrato comercial e mesocarpo de coco triturado (SC+MCT) (1:1), com tutor de xaxim; (4) substrato comercial e mesocarpo de coco triturado (1:1), utilizando tutor de MCT. A altura ou comprimento da planta, diâmetro do caule, número de nós, número de folhas, área foliar, volume de raízes subterrâneas e teor de nutrientes foram avaliados. Os melhores resultados para as características morfológicas foram observados nas plantas cultivadas com tutores de MCT e substrato $\mathrm{SC}+\mathrm{MCT}$. Entretanto, o maior teor de nitrogênio foliar foi observado nas plantas cultivadas com tutor MCT e substrato SC. O tratamento com tutor xaxim e substrato $\mathrm{SC}+\mathrm{MCT}$ foi o menos adequado para o cultivo de singônio e apresentou os menores valores para todas as características avaliadas.
\end{abstract}

Palavras-chave: Syngonium angustatum, casca de coco, xaxim.

\begin{abstract}
Growth of arrowhead plants with different supporting sticks and potting media

Two different supporting sticks and potting media were used to evaluate the growth of arrowhead plant (Syngonium angustatum Schott), in a completely randomized block design, in a factorial scheme $(2 \times 2)$ with six replicates, and three pots per plot. There were evaluated the (1) commercial substrate (SC) as potting medium, with fern tree supporting sticks (X); (2) commercial substrate as potting medium (SC), with coconut mesocarp supporting sticks (MCT); (3) commercial substrate and coconut mesocarp (SC+MCT) $(1: 1)$ as potting medium, with fern tree supporting sticks $(\mathrm{X})$; (4) commercial substrate and coconut mesocarp (1:1) as potting medium (SC+MCT), using coconut mesocarp supporting sticks (MCT). Plant height or length, stem diameter, number of nodes and of leaves, leaf area, subterranean root volume and nutrient contents were evaluated. The best results for the morphological characteristics were observed in plants grown under MCT supporting sticks and the SC+MCT potting medium; nevertheless the highest leaf $\mathrm{N}$ content was observed in plants grown under MCT supporting sticks and SC potting medium. The treatment with fern tree supporting sticks and SC+MCT potting medium was the least adequate one for growing Syngonium angustatum and presented the lowest values for all variables studied.
\end{abstract}

Keywords: Syngonium angustatum, fern tree, plant supporting sticks.

(Recebido para publicação em 12 de julho de 2003 e aceito em 17 de novembro de 2003)

$\mathrm{A}$ propagação e cultivo de plantas ornamentais requer a utilização de substratos que devem ter boa estrutura e porosidade, conseqüentemente boa aeração e retenção de água, baixa densidade, facilitando o manuseio e transporte, estando livre de patógenos e pragas (Hartmann e Kester, 1975; Kämpf, 2000).

Entre os substratos mais empregados no cultivo de ornamentais, merece destaque o xaxim, oriundo da espécie Dicksonia sellowiana que ocorre em meio às florestas da América Central e do Sul. O processo de produção do xaxim se inicia na extração ou corte das plantas, no interior do ecossistema florestal, com transporte aos locais de manufatura dos produtos a partir do tronco. A extração do xaxim nas florestas paranaenses e sua exploração econômica pela indústria artesanal e pelo comércio atacadista e varejista têm mantido uma curva de crescimento constante. Floricultores, paisagistas, urbanistas e, em maior número as donas-de-casa, são os principais consumidores dos artefatos do xaxim. A escassez da matéria-prima ainda não é sentida no varejo. Mas a indústria, para manter e até ampliar o volume de produção, tem arcado com custos de transporte cada vez maiores, uma vez que as florestas situadas em sua proximidade já não possuem mais estoques suficientes (Santos et al., 2000). O Paraná tem atendido boa parte da demanda de estados que não produzem xaxim e daqueles que já proibiram sua extração e comercialização, como é o caso de Santa Catarina e Rio Grande do Sul. Aproximadamente um milhão de vasos e mais uma quantidade não dimensionada de estacas, placas e pó de xaxim saem das fábricas e são distribuídos, pelos atacadistas, pratica- mente em todos os estados brasileiros (Santos et al., 2000).

Com lucratividade econômica elevada e mercado em contínua expansão, a exploração comercial do xaxim tem crescido e se fortalecido. A tendência é que, à medida que diminui a disponibilidade de matéria prima, o negócio torne-se ainda mais rentável, representando um ciclo que somente deixará de existir caso venha ocorrer a total extinção do xaxim das florestas do Paraná (Santos et al., 2000). Estudos com blocos de casca de coco fabricados especialmente para o uso como substrato de orquídeas epífitas, demonstraram que, do ponto de vista de retenção e perda de água, esse material, puro ou em mistura, pode substituir o xaxim (Demattê e Demattê, 1996). Parâmetros agronômicos têm indicado superioridade, ou no mínimo, igualdade de desempenho da 
fibra do mesocarpo do coco em relação a outros materiais (Merrow, 1994).

O singônio (Syngonium angustatum Schott) é planta semi-hebácea ascendente, de clima tropical, muito cultivada em vasos com tutores, para decorar ambientes internos ou como forração à meia sombra em jardins. Quando jovem, as folhas são simples e quando adultas passam a ter divisões no limbo. Seu maior atrativo comercial são as folhas que formam uma massa verde bem fechada. Sua facilidade de cultivo se deve ao fato da multiplicação ser feita por estacas herbáceas, durante todo o ano (Lorenzi e Souza, 2001), a única limitação é que a espécie não suporta temperaturas abaixo de $15^{\circ} \mathrm{C}$, podendo causar danos e levá-la a morte (Houseplant, 2002).

Nesse trabalho, avaliou-se o crescimento de singônio com tutores e, substrato à base de mesocarpo de coco, comparados aos materiais tradicionais (xaxim e substrato comercial).

\section{MATERIAL E MÉTODOS}

O trabalho foi realizado na área experimental da Universidade Estadual do Norte Fluminense Darcy Ribeiro, localizada no município de Campos dos Goytacazes, estado do Rio de Janeiro, situado a $21^{\circ} 44^{\prime} 47^{\prime}$ 'S, $41^{\circ} 18^{\prime} 24$ "W e altitude de aproximadamente $11 \mathrm{~m}$ em relação ao nível do mar.

Para o preparo do substrato e tutores de mesocarpo de coco triturado, as cascas de coco verde foram coletadas em pontos de venda de água de coco, na cidade de Campos dos Goytacazes. Os cocos foram descascados, retirando-se o epicarpo do fruto e em seguida, a parte fibrosa (mesocarpo) foi cortada e passada por uma máquina forrageira, e seca ao ar para uso como substrato. Para a confecção dos tutores, o mesocarpo de coco triturado foi colocado em uma fôrma feita de chapa de aço galvanizada, e prensado utilizando-se uma prensa hidráulica manual a $15.000 \mathrm{kgf}$ por $5 \mathrm{mi}$ nutos. Os tutores prontos foram colocados em estufa, com ventilação forçada, a $70^{\circ} \mathrm{C}$ durante 48 horas. Em seguida, realizou-se a imersão em solução na concentração de $50 \mathrm{~g} \mathrm{~kg}^{-1}$ de resina à base de formol e uréia, e secagem em estufa por mais 48 horas. Os tutores fo- ram submetidos à irrigação em vaso contendo substrato comercial por 21 dias. Aqueles que não se deformaram nem curvaram foram utilizados para o experimento com plantas.

Os tutores foram utilizados no cultivo de singônio (Syngonium angustatum Schott), em vasos plásticos de cor preta com capacidade para cinco litros e cultivados em casa de vegetação do tipo túnel, coberto com plástico leitoso $100 \mu \mathrm{m}$ e tela de sombreamento de $30 \%$, com abertura lateral (sombreamento de 70\%). O experimento foi montado sob delineamento inteiramente casualizado, em esquema fatorial $2 \times 2$, com 6 repetições e 3 vasos por parcela, compondo os tratamentos (1) substrato comercial (SC), com tutor de xaxim (X); (2) substrato comercial, com tutor de mesocarpo de coco triturado (MCT); (3) substrato comercial e mesocarpo de coco triturado (SC+MCT) (1:1), com tutor de xaxim; (4) substrato comercial e mesocarpo de coco triturado (1:1) e tutor de mesocarpo de coco triturado.

As mudas de singônio foram padronizadas, utilizando-se duas mudas de 25 $\mathrm{cm}$ ( $5 \mathrm{~cm}$ enterrados) de altura por vaso, com duas ou três folhas cada.

As plantas foram cultivadas durante 150 dias, de 20/02 (plantio) a 20/07/ 2001 (final do experimento). Foram avaliados a cada trinta dias a altura da planta (com o auxílio de trena); diâmetro do caule [a $10 \mathrm{~cm}$ de altura, com paquímetro digital (Electronic Digital Caliper)]; número de nós; número de folhas e área foliar [com uso de medidor de área foliar portátil (LI-300A Portable Area Meter-LI-COR Inc)]. No plantio e no final do experimento avaliou-se o estado nutricional das plantas. As raízes subterrâneas foram cuidadosamente lavadas em água corrente para remoção dos substratos e a área superficial foi determinada pela multiplicação da estimativa da área transversal, medida em medidor de área foliar(LI-3100, LI-COR Inc), pelo valor $\pi$ no final do experimento (Rossiello et al., 1995).

Foram analisados os teores de nutrientes do substrato comercial, do mesocarpo de coco triturado, das folhas de singônio, do tutor de xaxim, do tutor de MCT e também do substrato xaxim a título de comparação com o MCT, antes do plantio do experimento e no final. Todos os materiais foram submetidos às digestões úmidas (sulfúrica e nitroperclórica), separadamente (Malavolta et al., 1989; Jones et al., 1991). O pH e a condutividade elétrica (CE) foram determinados em água, como para solos (Tedesco et al., 1985).

$\mathrm{O}$ nitrogênio ( $\mathrm{N}$-org) foi determinado pelo método de Nessler (Jackson, 1965), o fósforo (P) pela redução do complexo fosfo-molíbdico pela vitamina C (Braga e Defelipo, 1974); para o nitrato $\left(\mathrm{NO}_{3}^{-}\right)$utilizou a metodologia descrita por Cataldo et al. (1975). O cloro $(\mathrm{Cl})$ foi determinado por titulometria (Malavolta et al., 1989). Os teores de potássio $(\mathrm{K})$ e de sódio $(\mathrm{Na})$ foram determinados por espectrofotometria de absorção atômica. $\mathrm{O}$ carbono total foi determinado no SC, X e MCT de acordo com a metodologia descrita por Anderson e Ingram (1996).

A temperatura média mínima, média máxima e umidade relativa do ar, durante o período de cultivo foram, respectivamente, de $22,5^{\circ} \mathrm{C}, 30,2^{\circ} \mathrm{Ce} 76,4 \%$.

\section{RESULTADOS E DISCUSSÃO}

Para o substrato MCT os valores de nutrientes foram: $\mathrm{N}$-org. $3,77 \mathrm{~g} \mathrm{~kg}^{-1}$, $\mathrm{NO}_{3}^{-} 0,85 \mathrm{~g} \mathrm{~kg}^{-1} ; \mathrm{P} 0,78 \mathrm{~g} \mathrm{~kg}^{-1} ; \mathrm{K} 11,66$ $\mathrm{g} \mathrm{kg}^{-1}$; Cl 7,053 $\mathrm{g} \mathrm{kg}^{-1}$ e Na $3122 \mathrm{mg} \mathrm{kg}^{-1}$; para o substrato comercial SC foram: $\mathrm{N}$ org. $12,28 \mathrm{~g} \mathrm{~kg}^{-1} ; \mathrm{NO}_{3}^{-} 0,197 \mathrm{~g} \mathrm{~kg}^{-1} ; \mathrm{P}$ $4,08 \mathrm{~g} \mathrm{~kg}^{-1} ; \mathrm{K} 5,16 \mathrm{~g} \mathrm{~kg}^{-1} ; \mathrm{Cl} 2,63 \mathrm{~g} \mathrm{~kg}^{-1} \mathrm{e}$ $\mathrm{Na} 162 \mathrm{mg} \mathrm{kg}^{-1}$ e para o substrato xaxim foram: N-org. 7,36 $\mathrm{g} \mathrm{kg}^{-1} ; \mathrm{NO}_{3}^{-} 0,05 \mathrm{~g}$

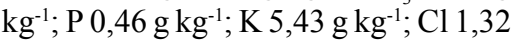
$\mathrm{g} \mathrm{kg}^{-1}$ e Na $55 \mathrm{mg} \mathrm{kg}^{-1}$. Os valores de $\mathrm{pH}$ foram: para o substrato MCT 4,52; para o substrato SC 5,40 e para o substrato $X$ 4,74. Os valores de condutividade elétrica $\left(\mathrm{mS} \mathrm{cm}^{-1}\right)$ foram: para o substrato MCT 6,44; para o substrato comercial SC 6,82 e para o substrato xaxim foi de 0,83 .

Os valores iniciais do $\mathrm{pH}$ dos substratos MCT e xaxim, foram menores do que o $\mathrm{pH}$ do substrato $\mathrm{SC}$, entretanto situaram-se dentro da faixa ideal recomendada (Conover, 1967) para substratos utilizados nos cultivos de plantas ornamentais, que, segundo Kämpf (1999), valores menores de $\mathrm{pH}$ 
Tabela 1. Teor de nutriente na matéria seca do substrato comercial e mesocarpo de coco triturado (SC+MCT) e substrato comercial (SC), aos 150 dias após o plantio de singônio. Campos dos Goytacazes, UENF, 2001.

\begin{tabular}{|c|c|c|c|c|}
\hline \multirow{2}{*}{ Nutriente } & \multirow{2}{*}{ Substrato } & \multicolumn{2}{|c|}{ Tutores } & \multirow{2}{*}{ Média } \\
\hline & & $\mathrm{X}$ & MCT & \\
\hline \multirow{3}{*}{$\mathrm{N}$ (org.) $\left(\mathrm{g} \mathrm{kg}^{-1}\right)$} & SC & 10,53 a $B$ & 14,01 a $A$ & 12,27 \\
\hline & $\mathrm{SC}+\mathrm{MCT}$ & 11,52 a $A$ & 9,15 b A & 10,34 \\
\hline & Média & 11,02 & 11,58 & C.V. $=23,85 \%$ \\
\hline \multirow{3}{*}{$\mathrm{NO}_{3}^{-}\left(\mathrm{g} \mathrm{kg}^{-1}\right)$} & SC & 0,31 & 0,26 & $0,29 \mathrm{a}$ \\
\hline & $\mathrm{SC}+\mathrm{MCT}$ & 0,17 & 0,13 & $0,15 \mathrm{a}$ \\
\hline & Média & $0,24 \mathrm{~A}$ & $0,20 \mathrm{~A}$ & C.V. $=54,31 \%$ \\
\hline \multirow{3}{*}{$P\left(\mathrm{~g} \mathrm{~kg}^{-1}\right)$} & $\mathrm{SC}$ & 4,39 & 4,54 & $4,47 \mathrm{a}$ \\
\hline & $\mathrm{SC}+\mathrm{MCT}$ & 2,56 & 2,72 & $2,64 \mathrm{~b}$ \\
\hline & Média & $3,47 \mathrm{~A}$ & $3,63 \mathrm{~A}$ & C.V. $=15,36 \%$ \\
\hline \multirow{3}{*}{$\mathrm{K}\left(\mathrm{g} \mathrm{kg}^{-1}\right)$} & SC & 4,22 & 4,73 & $4,47 \mathrm{a}$ \\
\hline & $\mathrm{SC}+\mathrm{MCT}$ & 2,76 & 2,76 & $2,76 \mathrm{~b}$ \\
\hline & Média & $3,49 \mathrm{~A}$ & $3,74 \mathrm{~A}$ & C.V. $=18,80 \%$ \\
\hline \multirow{3}{*}{$\mathrm{Cl}\left(\mathrm{g} \mathrm{kg}^{-1}\right)$} & SC & 1,15 & 0,81 & $0,97 \mathrm{a}$ \\
\hline & $\mathrm{SC}+\mathrm{MCT}$ & 0,62 & 0,63 & $0,63 \mathrm{~b}$ \\
\hline & Média & $0,88 \mathrm{~A}$ & $0,72 \mathrm{~A}$ & C.V. $=47,31 \%$ \\
\hline \multirow{3}{*}{$\mathrm{Na}\left(\mathrm{mg} \mathrm{kg}^{-1}\right)$} & SC & 333,33 & 266,66 & $300,00 \mathrm{a}$ \\
\hline & $\mathrm{SC}+\mathrm{MCT}$ & 260,00 & 303,33 & $281,66 a$ \\
\hline & Média & $296,66 \mathrm{~A}$ & $285,00 \mathrm{~A}$ & C.V. $=29,34 \%$ \\
\hline
\end{tabular}

*Médias seguidas da mesma letra não diferem entre si ao nível de 5\% de probabilidade pelo teste de Tukey: a e b na coluna comparam médias de substratos dentro do fator tutor; A e B na linha comparam médias de tutores dentro do fator substrato.

$\mathrm{X}$ : tutor de xaxim; MCT: tutor de mesocarpo de coco triturado.

podem alterar a disponibilidade de nutrientes e induzir sintomas de deficiência de N, K, Ca e Mg. Os valores de $\mathrm{pH}$ dos tratamentos que continham o mesocarpo de coco triturado como substrato ou em forma de tutores, não prejudicaram o crescimento das plantas de singônio. De maneira geral, os valores de $\mathrm{pH}$ estão de acordo com os valores citados por Demattê e Vitti (1997) e um pouco abaixo dos valores encontrados por Konduru et al. (1999). As folhagens são plantas mais tolerantes, sendo capazes de se adaptarem a essas condições (Kämpf, 1995).

Em relação à condutividade elétrica os valores elevados nos substratos $\mathrm{SC}$ e MCT se justificam pelo conteúdo de sais encontrados no SC podendo estar relacionado à adição de fertilizante na composição do substrato comercial. No MCT a condutividade elétrica reflete os níveis de $\mathrm{K}, \mathrm{Cl}$, e $\mathrm{Na}$ encontrados na sua composição. Esses resultados foram superiores aos obtidos por Handreck (1993) e Konduru et al. (1999).
Os altos teores de $\mathrm{Cl}$ e Na encontrados no MCT no início do experimento, não interferiram negativamente no crescimento das plantas, apesar dos teores foliares dos mesmos, aos 150 dias após o plantio (ponto de comercialização), encontrarem-se altos (Tabela 3), quando comparados ao nível crítico citado por Jones et al. (1991), indicando terem sido absorvidos sem ocasionar danos nas folhas e/ou raízes.

Os teores de nutrientes na casca de coco, bem como no xaxim, são muito variáveis, pois dependem da origem do material, afetada pelas condições de cultivo (estado nutricional, condições de clima e solo, luminosidades, idade da planta etc). Sendo assim, análises dos teores de $\mathrm{Na}$ e $\mathrm{Cl}$, principalmente, devem ser feitas antes de seu uso, pois esses elementos podem estar presentes acima do nível aceitável, prejudicando o efeito positivo deste resíduo na confecção de substratos. Prasad (1997) cita que o íon $\mathrm{Cl}$ pode ser prejudicial a culturas que são mais sensíveis à salinidade.
Devem ser conhecidas as necessidades das plantas que serão cultivadas, principalmente em relação aos íons $\mathrm{Cl}$ e Na (Röber, 1999). Evans et al. (1996), obtiveram teores de $\mathrm{K}, \mathrm{Cl}$ e $\mathrm{Na}$ elevados no mesocarpo de coco, possivelmente devido aos produtores utilizarem os fertilizantes $\mathrm{KCl}$ e $\mathrm{NaCl}$ no cultivo do coco.

Os teores de nitrogênio encontrados nos substratos aos 150 dias após o plantio (Tabela 1) mostraram que os maiores valores estavam presentes no substrato $\mathrm{SC}$ dos vasos que continham tutores MCT. Esses tutores MCT tinham uréia em sua composição (Tabela 2) e esta pode ter contribuído para elevar os teores de $\mathrm{N}$ encontrados naquele tratamento.

Os valores de nitrogênio encontrados no substrato SC encontram-se próximos àqueles citados por Rizzo et al. (1999). Para o MCT, os teores estão condizentes aos citados por Demattê e Vitti (1997), que analisaram o coxim.

$\mathrm{O}$ teor de $\mathrm{N}$-org nas folhas de singônio aos 150 dias após o plantio foi 
Tabela 2. Teor de nutrientes na matéria seca dos tutores de mesocarpo de coco triturado (MCT) e xaxim (X), aos 150 dias após o plantio de singônio. Campos dos Goytacazes, UENF, 2001.

\begin{tabular}{|c|c|c|c|c|}
\hline \multirow{2}{*}{ Nutriente } & \multirow{2}{*}{ Substrato } & \multicolumn{2}{|c|}{ Tutores } & \multirow{2}{*}{ Média } \\
\hline & & $\bar{x}$ & MCT & \\
\hline & SC & 6,16 & 30,49 & $18,33 \mathrm{a}$ \\
\hline \multirow[t]{3}{*}{$N$ (org.) $\left(\mathrm{g} \mathrm{kg}^{-1}\right)$} & $\mathrm{SC}+\mathrm{MCT}$ & 7,24 & 26,27 & 16,75 a \\
\hline & Média & $6,70 \mathrm{~B}$ & $28,38 \mathrm{~A}$ & C.V. $=23,31 \%$ \\
\hline & SC & 0,15 & 0,13 & $0,14 \mathrm{a}$ \\
\hline \multirow[t]{3}{*}{$\mathrm{NO}_{3}^{-}\left(\mathrm{g} \mathrm{kg}^{-1}\right)$} & $\mathrm{SC}+\mathrm{MCT}$ & 0,19 & 0,12 & $0,16 \mathrm{a}$ \\
\hline & Média & $0,17 \mathrm{~A}$ & $0,12 \mathrm{~B}$ & C.V. $=20,90 \%$ \\
\hline & SC & 0,25 & 0,73 & $0,49 \mathrm{a}$ \\
\hline \multirow[t]{3}{*}{$P\left(g_{k g}{ }^{-1}\right)$} & $\mathrm{SC}+\mathrm{MCT}$ & 0,28 & 0,72 & $0,50 a$ \\
\hline & Média & $0,26 \mathrm{~B}$ & $0,73 \mathrm{~A}$ & C.V. $=19,17 \%$ \\
\hline & SC & 2,15 a $B$ & 9,22 a $A$ & 5,68 \\
\hline \multirow[t]{2}{*}{$\mathrm{K}\left(\mathrm{g} \mathrm{kg}^{-1}\right)$} & $\mathrm{SC}+\mathrm{MCT}$ & 3,46 a $B$ & $7,53 \mathrm{~b} A$ & 5,50 \\
\hline & Média & 2,80 & 8,37 & C.V. $=23,85 \%$ \\
\hline
\end{tabular}

*Médias seguidas da mesma letra não diferem entre si ao nível de 5\% de probabilidade pelo teste de Tukey: a e b na coluna comparam médias de substratos dentro do fator tutor; A e B na linha comparam médias de tutores dentro do fator substrato.

$\mathrm{SC}$ : substrato comercial; SC+MCT: substrato comercial e mesocarpo de coco triturado.

Tabela 3. Teor de nutrientes na matéria seca das folhas de singônio, aos 150 dias após o plantio. Campos dos Goytacazes, UENF, 2001.

\begin{tabular}{|c|c|c|c|c|}
\hline \multirow{2}{*}{ Nutriente } & \multirow{2}{*}{ Substrato } & \multicolumn{2}{|c|}{ Tutores } & \multirow{2}{*}{ Média } \\
\hline & & $x$ & MCT & \\
\hline & SC & 26,79 a $B$ & 32,77 a $A$ & 29,78 \\
\hline \multirow[t]{3}{*}{$\mathrm{N}$ (org.) $\left(\mathrm{g} \mathrm{kg}^{-1}\right)$} & $\mathrm{SC}+\mathrm{MCT}$ & 15,12 b B & 27,40 b A & 21,26 \\
\hline & Média & 20,96 & 30,08 & C.V. $=10,35 \%$ \\
\hline & SC & 0,67 & 0,79 & $0,73 \mathrm{a}$ \\
\hline \multirow[t]{3}{*}{$\mathrm{NO}_{3}^{-}\left(\mathrm{g} \mathrm{kg}^{-1}\right)$} & $\mathrm{SC}+\mathrm{MCT}$ & 0,50 & 0,59 & $0,54 \mathrm{~b}$ \\
\hline & Média & $0,58 \mathrm{~A}$ & $0,69 \mathrm{~A}$ & C.V. $=25,04 \%$ \\
\hline & SC & $2,85 \mathrm{~b} \mathrm{~A}$ & 2,80 a $A$ & 2,82 \\
\hline \multirow[t]{3}{*}{$P\left(g_{k g}^{-1}\right)$} & $\mathrm{SC}+\mathrm{MCT}$ & 5,32 a $A$ & 3,38 a $B$ & 4,35 \\
\hline & Média & 4,08 & 3,09 & C.V. $=16,86 \%$ \\
\hline & $\mathrm{SC}$ & 34,50 & 40,88 & $37,69 a$ \\
\hline \multirow[t]{3}{*}{$\mathrm{K}\left(\mathrm{g} \mathrm{kg}^{-1}\right)$} & $\mathrm{SC}+\mathrm{MCT}$ & 27,18 & 30,88 & $29,03 \mathrm{~b}$ \\
\hline & Média & $30,84 \mathrm{~B}$ & $35,88 \mathrm{~A}$ & C.V. $=10,27 \%$ \\
\hline & SC & 5,88 & 4,10 & $4,99 \mathrm{a}$ \\
\hline \multirow[t]{3}{*}{$\mathrm{Cl}\left(\mathrm{g} \mathrm{kg}^{-1}\right)$} & $\mathrm{SC}+\mathrm{MCT}$ & 5,52 & 4,28 & $4,90 \mathrm{a}$ \\
\hline & Média & $5,70 \mathrm{~A}$ & 4,19 B & C.V. $=20,80 \%$ \\
\hline & SC & 798,33 & 946,66 & $872,50 \mathrm{a}$ \\
\hline \multirow[t]{2}{*}{$\mathrm{Na}\left(\mathrm{mg} \mathrm{kg}^{-1}\right)$} & $\mathrm{SC}+\mathrm{MCT}$ & 516,66 & 981,66 & 749,16 a \\
\hline & Média & $657,50 \mathrm{~B}$ & $964,16 \mathrm{~A}$ & C.V. $=32,85 \%$ \\
\hline
\end{tabular}

*Médias seguidas da mesma letra não diferem entre si ao nível de 5\% de probabilidade pelo teste de Tukey: a e b na coluna comparam médias de substratos dentro do fator tutor; A e B na linha comparam médias de tutores dentro do fator substrato.

SC: substrato comercial; SC+MCT: substrato comercial e mesocarpo de coco triturado; MCT: tutor de mesocarpo de coco triturado e X: tutor de xaxim. 
Tabela 4. Altura, diâmetro, número de nós, número de folhas e área foliar de plantas de singônio, cultivadas em vasos em função do substrato comercial (SC), substrato comercial e mesocarpo de coco triturado (SC+MCT) e do tutor de xaxim e mesocarpo de coco triturado (MCT) utilizado, aos 150 dias após o plantio. Campos dos Goytacazes, UENF, 2001.

\begin{tabular}{|c|c|c|c|c|}
\hline \multirow{2}{*}{ Nutriente } & \multirow{2}{*}{ Substrato } & \multicolumn{2}{|c|}{ Tutores } & \multirow{2}{*}{ Média } \\
\hline & & $\mathbf{x}$ & MCT & \\
\hline & SC & 53,09 a $A$ & 47,97 b A & 50,53 \\
\hline \multirow{3}{*}{ Altura $(\mathrm{cm})$} & $\mathrm{SC}+\mathrm{MCT}$ & 40,47 b B & 91,53 a $A$ & 66,00 \\
\hline & Média & 46,78 & 69,75 & C.V. $=17,57 \%$ \\
\hline & SC & 5,41 a $A$ & $5,33 \mathrm{~b} \mathrm{~A}$ & 5,38 \\
\hline \multirow[t]{3}{*}{ Diâmetro (mm) } & $\mathrm{SC}+\mathrm{MCT}$ & $4,23 \mathrm{~b} \mathrm{~B}$ & 5,99 a $A$ & 5,11 \\
\hline & Média & 4,82 & 5,66 & C.V. $=7,67 \%$ \\
\hline & SC & 13,84 a $A$ & 12,28 b A & 13,05 \\
\hline \multirow[t]{3}{*}{ Número de nós } & $\mathrm{SC}+\mathrm{MCT}$ & 10,89 b B & 20,61 a $A$ & 15,75 \\
\hline & Média & 12,36 & 16,44 & C.V. $=14,32 \%$ \\
\hline & SC & 12,19 a $A$ & 11,16 b A & 11,68 \\
\hline \multirow[t]{3}{*}{ Número de folhas } & $\mathrm{SC}+\mathrm{MCT}$ & 9,27 b B & 19,36 a $A$ & 14,32 \\
\hline & Média & 10,73 & 15,26 & C.V. $=16,04 \%$ \\
\hline & SC & 50,66 & 60,87 & $55,76 \mathrm{a}$ \\
\hline \multirow[t]{2}{*}{ Área foliar } & $\mathrm{SC}+\mathrm{MCT}$ & 28,72 & 52,78 & $40,75 \mathrm{~b}$ \\
\hline & Média & $39,69 \mathrm{~B}$ & $56,83 \mathrm{~A}$ & C.V. $=18,34 \%$ \\
\hline
\end{tabular}

*Médias seguidas da mesma letra não diferem entre si ao nível de 5\% de probabilidade pelo teste de Tukey: a e b na coluna comparam médias de substratos dentro do fator tutor; A e B na linha comparam médias de tutores dentro do fator substrato.

maior nos tratamentos com tutores de MCT (Tabela 3) independentemente do substrato, em decorrência do teor de Norg nos tutores (Tabela 2). Embora no substrato SC+MCT houvesse uma quantidade considerável de N-org (Tabela 1), as plantas nele cultivadas com tutor de xaxim mostraram-se amareladas por deficiência de N (Tabela 3), provavelmente devido à alta relação $\mathrm{C}: \mathrm{N}$ no MCT, que foi de 164 . Nesse caso, poderia estar ocorrendo utilização do $\mathrm{N}$ para decomposição do MCT, já que não foi feita suplementação de N. Conforme Röber (1999), o uso de cascas não decompostas, "verdes", e a não adição de nitrogênio leva a fixação do $\mathrm{N}$ do substrato e, conseqüentemente, deficiência de $\mathrm{N}$ nas plantas, por causa da alta relação $\mathrm{C}: \mathrm{N}$.

As mudas produzidas no substrato $\mathrm{SC}+\mathrm{MCT}$ e tutor de MCT alcançaram maiores valores de altura, diâmetro, número de nós e número de folhas (Tabela 4), o que pode estar relacionado à melhoria das características físicas do SC pela adição de MCT (baixa densidade do substrato, alta porosidade) e ao maior teor de $\mathrm{N}$ no tutor oriundo da re- sina à base de uréia na sua composição. As plantas do tratamento $\mathrm{SC}+\mathrm{MCT}$ e tutor de xaxim tiveram desempenho inferior em relação aos demais tratamentos, corroborando os resultados de teor foliar e sintomas visuais de deficiência de N (Tabela 3).

A área foliar das plantas no tratamento SC com tutor MCT foi maior (Tabela 4), com maior massa verde em relação aos demais tratamentos; podendo-se dizer que ele foi superior quanto ao padrão de qualidade, característica desejável para comercialização das plantas, já que o singônio é comercializado como folhagem ornamental. O segundo melhor tratamento em termos de qualidade de planta foi o $\mathrm{SC}+\mathrm{MCT}$ com tutor de MCT. O tradicionalmente utilizado pelos produtores que é o SC com tutor de xaxim foi o terceiro e, por último, o $\mathrm{SC}+\mathrm{MCT}$ com tutor de xaxim que apresentou o menor desenvolvimento de massa verde, possivelmente em virtude da restrição de $\mathrm{N}$ para o crescimento. Portanto, o tutor de MCT poderia substituir o de xaxim desde que fossem utilizados o $\mathrm{SC}$ ou $\mathrm{SC}+\mathrm{MCT}$ como substrato.
A área superficial de raízes das plantas de singônio aos 150 dias de cultivo com substrato composto pela mistura de $\mathrm{SC}+\mathrm{MCT}$ e com tutor de MCT foi 653,3 e com tutor de X foi de 650,5 . As plantas cultivadas em substrato $\mathrm{SC}$ e com tutor de MCT foi 181,9 e com o tutor de $\mathrm{X}$ foi de 304,5. A incorporação de substrato de MCT ao substrato comercial SC, favoreceu o crescimento das raízes subterrâneas das plantas de singônio, que apresentaram volumes superiores àqueles observados nas plantas cultivadas em substrato comercial $\mathrm{SC}$, evidenciando a influência benéfica da mistura do MCT ao SC na textura do substrato, o que, segundo Morgado (1998), é um fator determinante do crescimento e desenvolvimento das raízes.

Assim, conclui-se que para o crescimento das plantas de singônio, o tutor de MCT forneceu os nutrientes necessários durante todo o período de produção não havendo a necessidade de adubação até atingirem o ponto de comercialização e que o MCT pode ser utilizado em mistura com o SC reduzindo os gastos com substrato comercial, sem prejudicar o crescimento das plan- 
tas de singônio desde que sejam utilizados tutores de MCT.

\section{AGRADECIMENTOS}

À FAPERJ, UENF/LAMAV/LFIT, Setor de Nutrição Mineral de Plantas, Alba Química S. A., Tropiflora e Sr. José Accácio da Silva (TNS LFIT/CCTA/ UENF).

\section{LITERATURA CITADA}

ANDERSON, J.D.; INGRAM, J.S.I. Tropical soil biology and fertility: a handbook of methods. 2. ed. Wallingford: UK CAB International, 1996. 171 p.

BRAGA, J.M.; DEFELIPO, B.V. Determinação espectrofotométrica de fósforo em extratos de solos e material vegetal. Revista Ceres, Viçosa, v.21, p.73-85, 1974.

CATALDO, D.A.; HAROON, M.; SCHADER, L.E.; YOUNG, U.L. Rapid colorimetric determination of nitrate in plant tissue by nitration of salicylic acid. Communications in Soil Science Plant Analysis, v.6, p.71-80, 1975.

CONOVER, C.A. Soil amendment for pot and field grow flowers. Florida Flowers Grower, v.4, n.4, p.1-4, 1967.

DEMATTÊ, J.B.I.; DEMATTÊ, M.E.S.P. Estudos hídricos com substratos vegetais para cultivo de orquídeas epífitas. Pesquisa Agropecuária Brasileira, Brasília, v.31, p.803-813, 1996.

DEMATTÊ, M.E.S.P.; VITTI, G.C. Variação das concentrações de nutrientes em substratos vegetais para cultivo de orquídeas epífitas. In: $\mathrm{CON}$ GRESSO IBEROAMERICANO, 2, 1997, Vilamoura; CONGRESSO IBÉRICO DE CIÊNCIAS HORTÍCOLAS, 3, 1997, Vilamoura. Comunicações... Vilamoura: Associação Portuguesa de Horticultura,. Tomo 3, 63-68. (Actas de Horticultura, 17).
EVANS, M.R.; KNODURU, S.; STAMPS, R.H. Source variation in physical and chemical properties of coconut coir dust. Horticultural Science, v.31, p.965-967, 1996.

HANDRECK, K.A. Properties of coir dust, and its use in the formulation of soilless potting media. Communications in Soil Science Plant Analysis, v.24, p.349-363, 1993.

HARTMANN, H.T.; KESTER, D.E. Plant Propagation, principles and practices. 3. ed. New Jersey: Prentice-Hall, 1975. 662 p.

HOUSEPLANT: Syngonium. Disponível em $<$ http://www.houseplant.com/syngonium.html $>$. Acesso em 06 jan. 2002.

JACKSON, M.L. Soil chemical analysis. 5. ed. Englewood Cliffs: N.J. USA Prentice-Hall Inc., 1965. $498 \mathrm{p}$.

JONES, J.B.; WOLF, B.; MILLS, H.A. Plant Analysis Handbook. A practical sampling, preparation, analysis, and interpretation guide. Athens, Georgia: USA Micro-Macro Publishing Inc., $1991.213 \mathrm{p}$.

KÄMPF,A.N. Seleção de materiais para uso como substrato. In: KÄMPF, A.N.; FERMINO, M.H. (Eds.) Substratos para Plantas: a base da produção vegetal em recipientes. Porto Alegre: Gênesis, 1999. p.139-146.

KÄMPF, A.N. (Ed.) Manutenção de plantas ornamentais para interiores. 1. ed. Porto Alegre: Rígel, $1995112 \mathrm{p}$

KÄMPF, A.N. Produção comercial de plantas ornamentais. Guaíba: Agropecuária, 2000. 254 p. KONDURU, S.; EVANS, M.R.; STAMPS, R.H. Coconut husk and processing effects on chemical and physical properties of coconut coir dust. Hort Science, v.34, p.88-90, 1999.

LORENZI, H.; SOUZA, H.M. Plantas Ornamentais no Brasil. 3. ed. Nova Odessa-SP: Instituto Plantarum, 2001. $1088 \mathrm{p}$

MALAVOLTA, E.; VITTI, G.C.; OLIVEIRA, S.A. Avaliação do Estado Nutricional das Plantas. Principios e aplicações. Piracicaba: Associação Brasileira para Pesquisa da Potassa e do Fosfato (POTAFOS), 1989. $201 \mathrm{p}$.
MEEROW, A.W. Growth of two subtropical ornamentals using coir (coconut mesocarp pith) as a peat substitute. Hort Science, v.29, p.14841486, 1994.

MORGADO, I.F. Nova metodologia de produção de mudas de Eucalyptus grandis Hill ex Maiden e Saccharum spp utilizando resíduos prensados como substrato. 1998. 104 p. (Tese doutorado), UENF, Campos dos Goytacazes-RJ.

PRASAD, M. Physical, chemical and biological properties of coir dust. Acta Horticulturae, v.450, p.21-29, 1997.

RIZZO, A.A.N.; PÁDUA, J.G.; FERREIRA, M.R.; BRAZ, L.T. Efeito na formação de mudas em diferentes composições de substratos na produção de couve-flor. In: KÄMPF, A.N.; FERMINO, M.H. (Eds.) Substratos para Plantas: a base da produção vegetal em recipientes. Porto Alegre: Gênesis, 1999. p.203-209.

RÖBER, R. Substratos hortícolas: possibilidades e limites de sua composição e uso; exemplos da pesquisa, da indústria e de consumo. In: KÄMPF, A.N.; FERMINO, M.H. (Eds.) Substratos para Plantas: a base da produção vegetal em recipientes. Porto Alegre: Gênesis, 1999. p.123-138. ROSSIELLO, R.O.P.; ARAÚJO, A.P.; FERNANDES, M.S. Comparação dos métodos fotoelétricos e da interseção na determinação de área, comprimento e raio médio radicular. Pesquisa Agropecuária Brasileira, Brasília, v.30, n.5, p.633-638, 1995.

SANTOS, A.J.; CHOTGUIS, J.; MIELKE, E. Análise da cadeia produtiva do xaxim (Dicksonia selloviana) no Estado do Paraná. In: CONGRESSO E EXPOSIÇÃO INTERNACIONAL SOBRE FLORESTAS, 6., 2000, Porto Seguro. Anais.. Porto Seguro: 2000. p.233-234.

TEDESCO, M.J., VOLKWEISS, S.J., BOHNEN, H. Análises de solo, plantas e outros materiais. Porto Alegre: UFRGS, Departamento de Solos, 1985. 186 p. (Boletim Técnico). 